\title{
COVID-19 in a patient with Glanzmann Thrombasthenia: about a pediatric case
}

\author{
Laurent SATTLER ${ }^{1}$, Olivier Feugeas ${ }^{2}$, Claire Hager ${ }^{1}$, Lélia Grunebaum ${ }^{1}$, and Dominique \\ Desprez $^{2}$
}

${ }^{1}$ Hôpitaux universitaires de Strasbourg

${ }^{2}$ Hopitaux universitaires de Strasbourg

July 29, 2020

\begin{abstract}
The coagulopathy associated with Coronavirus disease 2019 (COVID-19) leads to a thrombotic burden. To date, solely interim thromboprophylaxis guidance have been established, gaps in evidence are remaining, especially for ambulatory COVID-19 patients. We report a case COVID-19 in a patient with Glanzmann thrombasthenia, a rare platelet disorder associated with a high bleeding tendency. Our experience emphasizes the difficulty to manage such a condition, given the balance between thrombotic and bleeding tendencies, and the unavailability of evidence-based guidelines. Moreover, we detail hereinafter how patient's bleeding disorder made COVID-19 diagnosis very difficult, thus highlighting the limits in actual SARS-CoV-2 molecular assays.
\end{abstract}

\section{Hosted file}

COVID-19 in a patient with Glanzmann Thrombasthenia - PBC - Main.doc available at https: //authorea.com/users/347112/articles/472927-covid-19-in-a-patient-with-glanzmannthrombasthenia-about-a-pediatric-case

\section{Hosted file}

COVID-19 in a patient with Glanzmann Thrombasthenia - PBC - Table 1.doc available at https://authorea. com/users/347112/articles/472927-covid-19-in-a-patient-with-glanzmannthrombasthenia-about-a-pediatric-case 